\title{
Prevalence of Depression in Ankylosing Spondylitis: A Systematic Review and Meta-Analysis
}

\author{
Lijuan Zhang ${ }^{1}$, Yaping $\mathrm{Wu}^{2}$, Shiguang Liu ${ }^{凶}$, and Weiyi Zhu ${ }^{3 凶}$ \\ ${ }^{1}$ Department of Gastrointestinal Surgery, Shanghai Minimally Invasive Surgery Center, Ruijin Hospital, Shanghai Jiao Tong University \\ School of Medicine, Shanghai, China \\ ${ }^{2}$ Department of Rheumatology, Ruijin Hospital, Shanghai Jiao Tong University School of Medicine, Shanghai, China \\ ${ }^{3}$ Department of Nursing, Ruijin Hospital, Shanghai Jiao Tong University School of Medicine, Shanghai, China
}

The aim of this study was to provide a summary estimate of depression prevalence among people with ankylosing spondylitis (AS) in comparison to those without AS. A systematic literature search was conducted using PubMed, Embase, PsycINFO, Web of Science, the Cochrane database library, China National Knowledge Infrastructure, and Wanfang Database from their inception to December 2016. The results showed that thirty-one eligible studies involving 8,106 patients were analyzed. Fifteen methods of defining depression were reported. The overall pooled prevalence of depression was 35\% (95\% CI, 28-43\%), with high between-study heterogeneity $\left(\mathrm{I}^{2}=98.8 \%\right.$, $\mathrm{p}<0.001$ ). The relative risk of depression among people with AS was 1.76 (95\% CI: $1.21-2.55$, eight studies, $\mathrm{n}=3,006)$ compared with people without AS. The depression score [standardized mean difference (SMD) $=0.43,95 \%$ CI: $0.19-0.67$, seven studies, $\mathrm{n}=549$ ] was higher in AS patients than in controls. The main influence on depression prevalence was the sample size and country of origin. In conclusion, one-third of people with AS experience symptoms of depression. Depression was more prevalent in AS patients than in controls. Further research is needed to identify effective strategies for preventing and treating depression among AS patients.

Psychiatry Investig 2019;16(8):565-574

Key Words Ankylosing spondylitis, Depression, Meta-analysis, Systematic review.

\section{INTRODUCTION}

Ankylosing spondylitis (AS) is a chronic inflammatory rheumatic disease with significant effects on patients' physical function and psychological status. ${ }^{1,2}$ It has become increasingly clear that psychological distress, such as depression or anxiety, is common in patients with including osteoarthritis, ${ }^{3}$ lupus $^{4}$ and rheumatic arthritis. ${ }^{5,6}$ Individuals with AS are more likely to be depressed than healthy individuals. ${ }^{7}$ Depression is a chronic, prevalent condition, and is a leading cause of dis-

\footnotetext{
Received: February 7, 2019 Revised: April 29, 2019

Accepted: June 5, 2019

$\triangle$ Correspondence: Shiguang Liu, MD

Department of Gastrointestinal Surgery, Shanghai Minimally Invasive Surgery Center, Ruijin Hospital, Shanghai Jiao Tong University School of Medicine, 197, Ruijin Er Road, Shanghai 200025, China

Tel: +86 13816620328, Fax: +86 54314096, E-mail: 94262369@qq.com

$\triangle$ Correspondence: Weiyi $\mathrm{Zhu}, \mathrm{PhD}$

Department of Nursing, Ruijin Hospital, Shanghai Jiao Tong University School of Medicine, 197, Ruijin Er Road, Shanghai 200025, China

Tel: +86 13621672696, Fax: +86 54314096, Email: venyzwy@163.com

(c) This is an Open Access article distributed under the terms of the Creative Commons Attribution Non-Commercial License (https://creativecommons.org/licenses/by$\mathrm{nc} / 4.0$ ) which permits unrestricted non-commercial use, distribution, and reproduction in any medium, provided the original work is properly cited.
}

ability, affecting at least 120 million people worldwide. ${ }^{8}$ In a population based study, doctor-diagnosed depression was found to be increased 1.81 and 1.49 fold respectively in women and men with AS. ${ }^{9}$ It may be explained that AS is related to inflammation of depression because it is an inflammatory disease. Depressed AS patients tended to have poor long-term outcomes, including increased disease activity, ${ }^{10,11}$ fatigue, ${ }^{12}$ decreased functionality, ${ }^{13}$ sleep disturbances, ${ }^{14}$ impaired quality of life, ${ }^{15}$ and high medical costs. ${ }^{16}$ However, estimates of the prevalence of depression in AS patients varied across studies, from $3 \%{ }^{17}$ to $66 \%{ }^{18}$ Such discrepancy could be explained by the differences in time frames when these studies were performed, study quality, or tools used for assessing depression. It is important for rheumatologists to establish reliable estimate of depression prevalence, in order to prevent, treat, and identify causes of depression in people with AS. Recent reviews have suggested that depression was highly prevalent among people with rheumatoid arthritis, ${ }^{19}$ osteoarthritis, ${ }^{3}$ and systemic lupus erythematosus. ${ }^{20}$ Another systematic review found that the prevalence of neuropsychiatric damage in chronic rheumatic diseases such as lupus has been significantly in- 
creasing over the past 5 decades. ${ }^{21}$ This finding is not surprising due to reduction in white matter and grey matter volumes in the very early stage of lupus. ${ }^{22}$ As yet no systematic review has provided pooled prevalence estimates of depression in AS. Our goal was to fill this gap. We aimed to 1) describe the pooled prevalence of depression in people with AS; 2) compare depression prevalence and score in AS patients versus healthy controls; 3 ) explore the influence of study characteristics on prevalence estimates.

\section{METHODS}

This systematic review was conducted according to the Preferred Reporting Items for Systematic Reviews and MetaAnalyses (PRISMA) standard ${ }^{23}$ and followed a predetermined registered protocol (PROSPERO: 42016052590).

\section{Search strategy}

The systematic literature search was conducted by two investigators independently through the PubMed, Embase, PsycINFO, Web of Science, Cochrane database library, China National Knowledge Infrastructure (CNKI), and Wanfang Database for pertinent studies published in English or Chinese from their inception to December 2016. The computer-based searches combined terms related to AS patients [(depress* or depress* disorder $\$$ or affective disorder $\$$ or mood disorder $\$$ or adjustment disorder\$ or affective symptom\$ or dysthymi*) AND (Ankylosing spondylitis or AS)] (Supplementary Material 1 in the online-only Data Supplement). The search was restricted to studies in humans. In addition, the reference lists of all identified relevant publications were reviewed. Finally, where published information was unclear or inadequate, we contacted the corresponding authors for more information.

\section{Inclusion and exclusion criteria}

Studies were eligible if they met the following criteria: 1) observational studies (cross-sectional and prospective studies) and baseline data of randomized controlled trials with or without a comparison group without AS; 2) depression was measured by self-reported symptom scales, physician/clinician diagnosis, or structured clinical diagnostic interview. Table 1 presented a full list of the eligible methods of detecting depression, alongside the numbers of participants assessed.

Studies were excluded if: 1) the study was not published as the full reports, such as case reports, commentaries, conference abstracts and letters to editors; 2) the study had a retrospective design; and 3) participants with depression at baseline were not excluded for the analysis.

\section{Data extraction and quality assessment}

Two trained investigators independently extracted data and assess quality of the studies included in this meta-analysis. Any disagreements in data extraction and quality assessment were resolved through discussion between the two investigators or adjudication with a third reviewer. We used a standardized form to record data on the authors, year of publication, country of study, participants, percentage of male participants, average age of participants, mean disease duration, criteria for detection of depression, and reported the prevalence or score of depression. If duplicate publications from the same study were identified, we would include the result with the largest number of individuals from the study. Wherever possible, we extracted the number affected and not affected by depression in each sample (using the authors' cut-off points for each outcome measure). If this was not available, we extracted the mean and standard deviation of the depression assessment scale. The investigators independently fulfilled the quality assessment using a modified version of the Newcastle-Ottawa Scale (NOS) in line with previous study. ${ }^{24}$ Studies were judged to be at low risk of bias ( $\geq 3$ points) or high risk of bias ( $<3$ points).

\section{Outcome measures}

The outcomes of interest were major depression diagnosed with a structured clinical assessment [e.g., International Classification of Diseases (ICD)-10] or depression assessed with

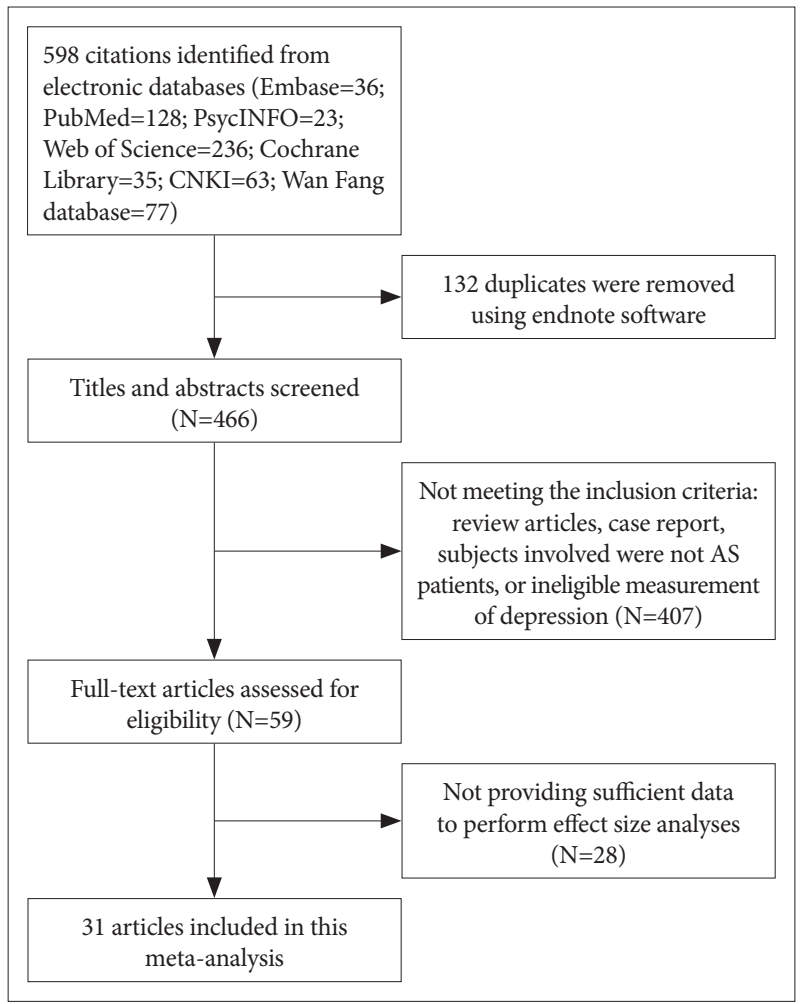

Figure 1. Search results and study selection. 


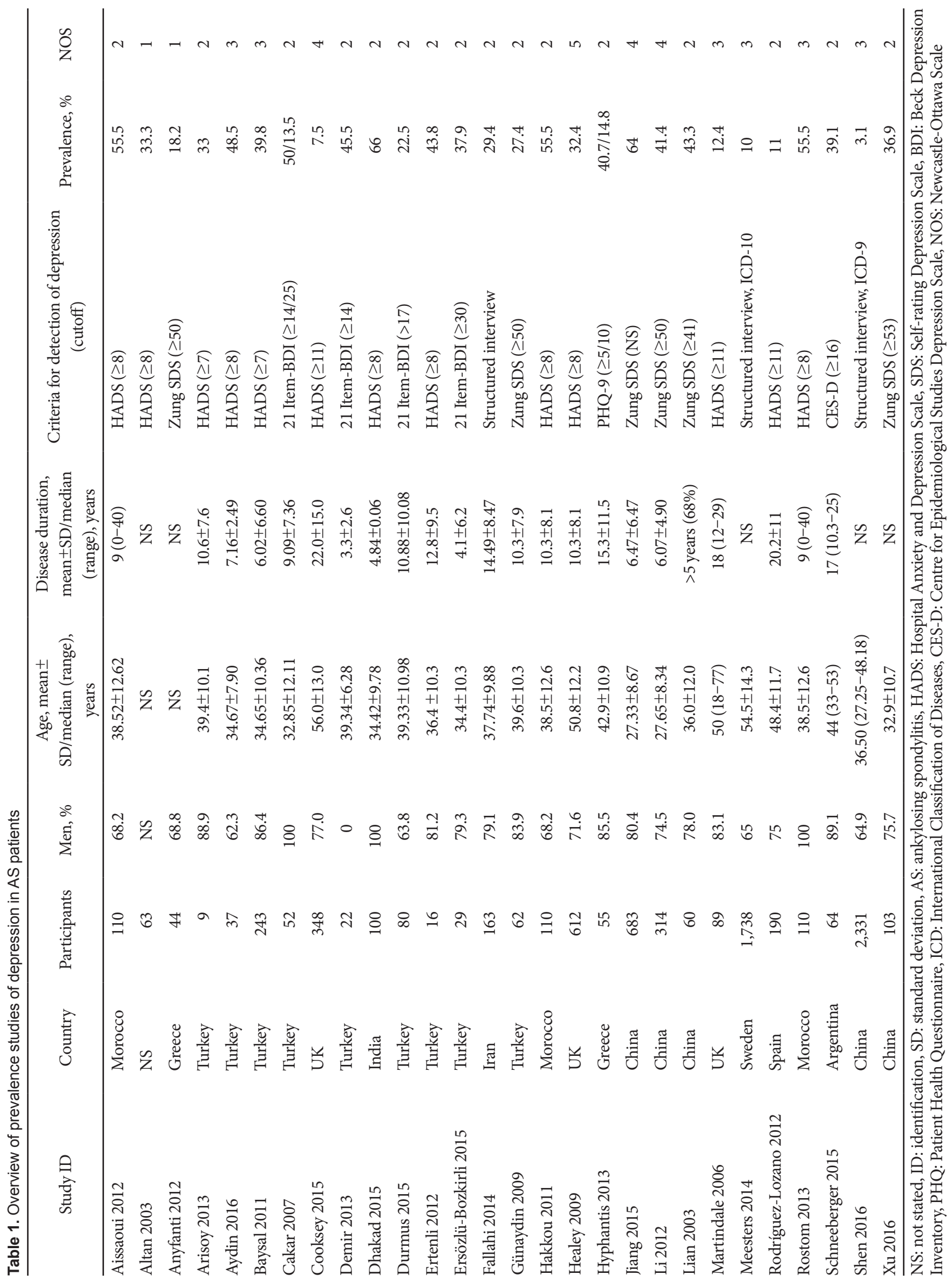


a validated assessment tool or screening measure [e.g., the Hospital Anxiety and Depression Scale (HADS), Beck Depression Inventory (BDI)].

\section{Statistical analyses}

Three analyses were undertaken. First, we pooled studies reporting the prevalence of depression in the AS sample using a random-effects models. ${ }^{25,26}$ Second, we used a pooled relative risk (RR) analysis with random-effect model. Third, we conducted a pooled standardized mean difference (SMD) analysis to investigate differences between those with and without AS. Statistical heterogeneity among studies was evaluated with $\mathrm{I}^{2}$ statistics with the values of $25 \%, 50 \%$, and $75 \%$ respectively denoted cut-off points for low, moderate and high degrees of heterogeneity. ${ }^{27}$ The influence of individual studies on the overall prevalence estimate was explored by serially excluding each study in a sensitivity analysis. Subgroup analyses were planned by overall study quality, sample size, country of origin and publication year to explore the sources of potential heterogeneity. Finally, we used Pearson's and Spearman's correlation analyses to assess the association between variables and prevalence of depression in people with AS. Potential publication bias was evaluated with a funnel $\operatorname{plot}^{28}$ and the Egger's test. ${ }^{29}$ Statistical analyses were all conducted on Statistical analyses were all conducted on STATA version 12.0 (Stata Corp, College Station, TX, USA).

\section{RESULTS}

\section{Search results}

A total of 598 citations were identified. After removal of duplicates, titles and then abstracts were screened for potential eligibility. From this, 59 were potentially eligible and considered in the full-text review. Twenty-eight articles were excluded; thus, 31 records met the eligibility criteria and were included (Figure 1), and a full reference list was shown in Supplementary Material 2 (in the online-only Data Supplement). Inter-observer agreement $(\kappa)$ between two investigators was 0.89 .

\section{Study characteristics}

Table 1 and 2 presented the characteristics of the included studies. Thirty-one eligible studies consisted of 8,106 patients were reported. Nineteen studies were conducted in Asia, 7 studies in Europe, 3 studies in Africa, and 1 study in South America. The mean age was 39.2 years, and the mean percentage of males represented in the sample was $75.9 \%$. In addition, the mean number of participants per study was 261 , and the mean disease duration was 10.64 years. Table 3 described the methods defined depression and the frequency of their use. Depres-

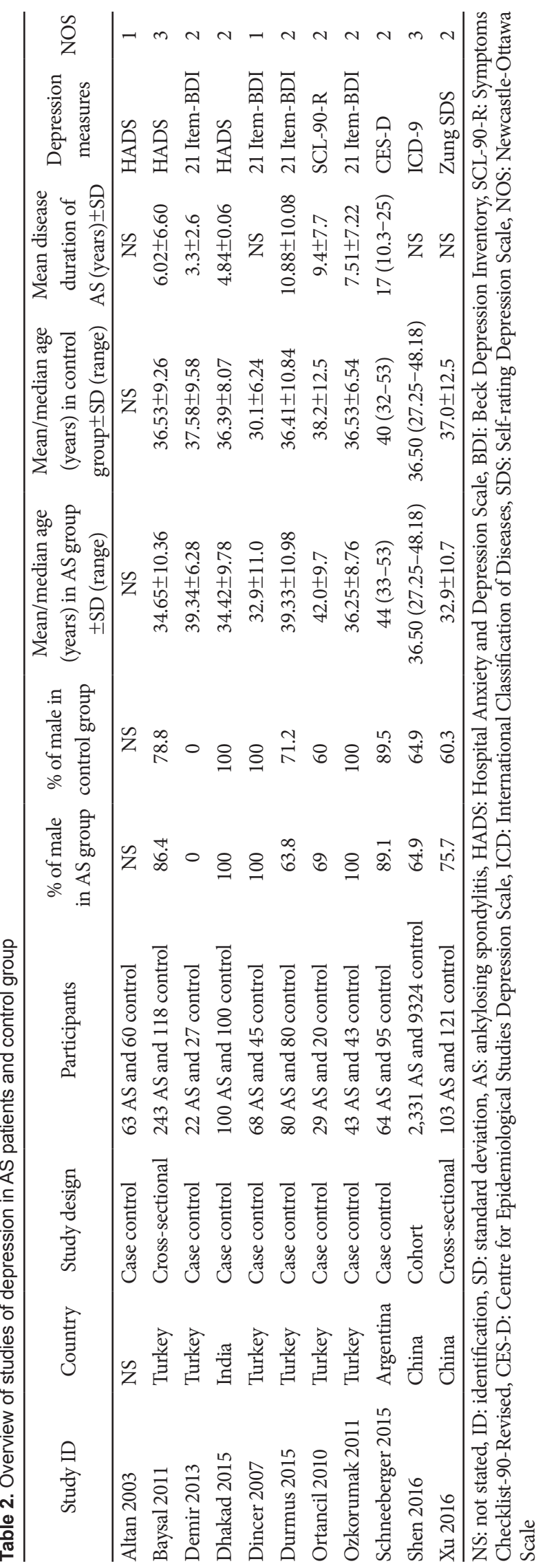


Table 3. Methods of detecting depression and summary of prevalence and heterogeneity findings

\begin{tabular}{|c|c|c|c|c|c|}
\hline Tool & Definition/cutoff & No. of studies & No. of participants & Prevalence, \% (95\% CI) & Heterogeneity $I^{2}, \%$ \\
\hline \multirow[t]{3}{*}{ HADS } & $\geq 7$ & 2 & 252 & $40(34-46)$ & 0 \\
\hline & $\geq 8$ & 8 & 1,158 & $42(39-45)$ & 91.1 \\
\hline & $\geq 11$ & 3 & 627 & $9(6-12)$ & 29.6 \\
\hline \multirow[t]{4}{*}{21 Item-BDI } & $\geq 14$ & 2 & 74 & $49(34-60)$ & 0 \\
\hline & $>17$ & 1 & 80 & $22(13-32)$ & - \\
\hline & $\geq 25$ & 1 & 52 & $14(4-23)$ & - \\
\hline & $\geq 30$ & 1 & 29 & $38(20-56)$ & - \\
\hline \multirow[t]{4}{*}{ Zung SDS } & $>41$ & 1 & 60 & $43(31-56)$ & - \\
\hline & $\geq 50$ & 3 & 420 & $30(15-44)$ & 87.0 \\
\hline & $\geq 53$ & 1 & 103 & $37(28-46)$ & - \\
\hline & NS & 1 & 683 & $64(60-68)$ & - \\
\hline Structured interview (e.g., ICD) & & 3 & 4,232 & $13(6-20)$ & 98.4 \\
\hline CES-D & $\geq 16$ & 1 & 64 & $39(27-51)$ & - \\
\hline \multirow[t]{2}{*}{ PHQ-9 } & $\geq 5$ & 1 & 55 & $41(28-54)$ & - \\
\hline & $\geq 10$ & 1 & 55 & $15(5-24)$ & - \\
\hline
\end{tabular}

NS: not stated, HADS: Hospital Anxiety and Depression Scale, BDI: Beck Depression Inventory, SDS: Self-rating Depression Scale, ICD: International Classification of Diseases, CES-D: Centre for Epidemiological Studies Depression Scale, PHQ: Patient Health Questionnaire

sion was assessed in 15 different ways. Thirteen studies assessed for depression using the HADS; three different cut-off points were presented, the most commonly used being 8 . Five studies assessed for depression using the 21 Item-BDI, with four different thresholds were presented in the articles. Six used the Zung Self-rating Depression Scale (SDS), and three used other screening tools. Three assessed for depression using structured interview (e.g., ICD). Supplementary Table 1 (in the online-only Data Supplement) summarized the quality assessment using a modified version of the NOS, which indicated that 1 study received 5 points, 3 studies received 4 points, 6 studies received 3 points, 18 studies received 2 points, and 3 studies received 1 point.

\section{Prevalence of depression among AS patients}

Prevalence estimates of depression varied from 3\% to $66 \%$ in individual studies (Table 1). The overall pooled prevalence of depression was 35\% (95\% CI, 28-43\%), with high betweenstudy heterogeneity $\left(\mathrm{I}^{2}=98.8 \%, \mathrm{p}<0.001\right)$ (Figure 2 ). Table 3 presented the summary of meta-analyses and heterogeneity assessments. Prevalence estimates ranged from 9\% (95\% CI, $6-12 \%, \mathrm{I}^{2}=29.6 \%$ ) according to the Hospital Anxiety and Depression Scale with thresholds of $11 \%$ to $49 \%$ (95\% CI, 34$60 \%, \mathrm{I}^{2}=0 \%$ ) for the 21 -Item Beck Depression Inventory with a cutoff of 14 or more. Prevalence of major depressive disorder to be $13 \%$ (95\% CI, 6-20\%) according to the structured interview, with high heterogeneity $\left(\mathrm{I}^{2}=98.4 \%\right)$.

\section{Depression in AS versus non-AS cohorts}

Eight studies included data on the prevalence estimates of depression for people with AS compared with those without AS. A pooled RR of 1.76 (95\% CI: 1.21-2.55, n=3006) (Figure 3). Seven studies $(n=549)$ presented data comparing depression scores for people with AS compared with those without AS. The depression score (SMD=0.43, 95\% CI: 0.19-0.67) was higher in AS patients than in controls (Figure 4).

\section{Sensitivity and subgroup analyses}

Table 4 showed the prevalence estimates of depression according to each sensitivity and subgroup analysis, in comparison with the primary analysis. Sensitivity analyses found that the exclusion of studies with less sample representativeness tended to decrease depression prevalence estimates according to structured interview. The pooled SMD tended to decrease in AS patients verse controls by exclusion of studies only using male sample. The subgroup analyses were conducted by sample size, overall quality, publication year, and country of origin. The results showed that studies with sample size $<200$ had higher depression prevalence estimates [52\% (95\% CI, 44-60\%) vs. $42 \%$ (95\% CI, 39-45\%)] compared with primary analysis according to the HADS with thresholds of 8 , and higher pooled RR [3.72 (95\% CI, 1.33-10.38) vs. 1.48 (95\% CI, 1.06-2.06)] in AS patients verse controls compared with the studies with sample size $\geq 200$. When evaluated by Newcastle-Ottawa Scale (NOS), studies with lower total overall quality scores yielded higher depression estimates [52\% (95\% CI, $41-63 \%)$ vs. $45 \%$ (95\% CI, 28-62\%)] accord- 


\begin{tabular}{|c|c|c|c|}
\hline $\begin{array}{l}\text { Study } \\
\text { ID }\end{array}$ & & ES $(95 \% \mathrm{CI})$ & $\begin{array}{c}\% \\
\text { Weight }\end{array}$ \\
\hline Aissaoui 2012 & $\rightarrow$ & $0.56(0.46,0.65)$ & 3.69 \\
\hline Altan 2003 & 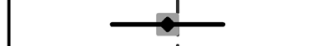 & $0.33(0.22,0.45)$ & 3.57 \\
\hline Anyfanti 2012 & I & $0.18(0.07,0.30)$ & 3.58 \\
\hline Arisoy 2013 & 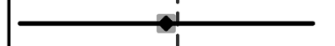 & $0.33(0.02,0.64)$ & 2.30 \\
\hline Aydin 2016 & + & $0.49(0.32,0.65)$ & 3.29 \\
\hline Baysal 2011 & $\frac{1}{1}$ & $0.40(0.34,0.46)$ & 3.82 \\
\hline Cakar 2007 & - & $0.50(0.36,0.64)$ & 3.45 \\
\hline Cooksey 2015 & 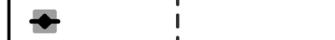 & $0.08(0.05,0.10)$ & 3.91 \\
\hline Demir 2013 & $T$ & $0.46(0.25,0.66)$ & 2.97 \\
\hline Dhakad 2015 & $\rightarrow$ & $0.66(0.57,0.75)$ & 3.69 \\
\hline Durmus 2015 & $\longrightarrow$ & $0.22(0.13,0.32)$ & 3.70 \\
\hline Ertenli 2012 & 1 & $0.44(0.19,0.68)$ & 2.72 \\
\hline Ersozlü-Bozkirli 2015 & 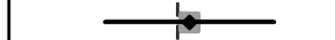 & $0.38(0.20,0.56)$ & 3.19 \\
\hline Fallahi 2014 & $\perp$ & $0.29(0.22,0.36)$ & 3.79 \\
\hline Günaydin 2009 & ; & $0.27(0.16,0.39)$ & 3.60 \\
\hline Hakkou 2011 & — & $0.56(0.46,0.65)$ & 3.69 \\
\hline Healey 2009 & & $0.32(0.29,0.36)$ & 3.89 \\
\hline Hyphantis 2013 & & $0.41(0.28,0.54)$ & 3.49 \\
\hline Jiang 2015 & $\rightarrow$ & $0.64(0.60,0.68)$ & 3.89 \\
\hline Li 2013 & - & $0.41(0.36,0.47)$ & 3.84 \\
\hline Lian 2003 & & $0.43(0.31,0.56)$ & 3.51 \\
\hline Martindale 2006 & $\rightarrow$ & $0.12(0.06,0.19)$ & 3.79 \\
\hline Meesters 2014 & $\bullet$ & $0.10(0.09,0.11)$ & 3.92 \\
\hline Rodríguez-Lozano 2012 & $\rightarrow$ & $0.11(0.07,0.15)$ & 3.87 \\
\hline Rostom 2013 & 1 & $0.56(0.46,0.65)$ & 3.69 \\
\hline Schneeberger 2015 & & $0.39(0.27,0.51)$ & 3.55 \\
\hline Shen 2016 & $\bullet$ & $0.03(0.02,0.04)$ & 3.93 \\
\hline Xu 2016 & & $0.37(0.28,0.46)$ & 3.69 \\
\hline Overall (I-squared=98.8\%, $\mathrm{p}=0.000$ ) & & $0.35(0.28,0.43)$ & 100.00 \\
\hline Note: weights are from random effects analysis & 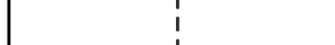 & & \\
\hline-0.753 & \multicolumn{3}{|c|}{0.753} \\
\hline
\end{tabular}

Figure 2. Prevalence of depression in ankylosing spondylitis patients.

ing to the HADS with thresholds of 8 , and higher pooled RR [3.72 (95\% CI, 1.33-10.38) vs. 1.48 (95\% CI, 1.06-2.06)] compared with the studies with higher total overall quality scores. More recent publications and developing country tended to yield higher depression prevalence estimates according to the HADS with a cutoff of 8 or more. There was no particular trend or pattern in any other sensitivity analyses or subgroup analyses.

\section{Associated study variables}

Pearson's and Spearman's correlation analyses were employed to examine the relationship between variables including proportion of male participants, mean/medium age, mean/medium disease duration, sample size, representativeness, comparability, overall quality, country of origin, publication year, and the prevalence of depression. We found that small sample size $(\mathrm{r}=-0.45, \mathrm{p}=0.016)$ and developing country $(\mathrm{r}=0.613, \mathrm{p}=0.001)$ of the sample were significantly associated with increased de- pression prevalence (Table 5).

\section{Assessment of publication bias}

According to the Egger's test, assessment of publication bias suggested significant publication bias in studies reporting depression [Egger: bias=7.87 (95\% CI: 4.77-10.97), $\mathrm{p}<0.001$ ] (Supplementary Figure 1 in the online-only Data Supplement).

\section{DISCUSSION}

This is the first systematic review and meta-analysis on the prevalence of depression in AS. This study indicated that depression were more prevalent in AS patients than in controls. In this study, the pooled prevalence of depression in AS patients is $35 \%$ and higher than other chronic medical illnesses such as asthma (27\%), ${ }^{30}$ chronic obstructive lung disease (24.6\%), lupus $(24 \%)^{20}$ and rheumatoid arthritis (15\%). ${ }^{32}$ This metaanalysis also revealed that small sample size and developing 


\begin{tabular}{|c|c|c|c|}
\hline $\begin{array}{l}\text { Study } \\
\text { ID }\end{array}$ & & RR (95\% CI) & $\begin{array}{c}\% \\
\text { Weight }\end{array}$ \\
\hline Altan 2003 & & $1.25(0.70,2.24)$ & 12.91 \\
\hline Baysal 2011 & & $1.08(0.79,1.47)$ & 16.70 \\
\hline Demir 2013 & & $0.88(0.45,1.68)$ & 11.96 \\
\hline Dhakad 2015 & - & $13.65(4.41,42.28)$ & 6.93 \\
\hline Durmus 2015 & & $5.08(1.55,16.65)$ & 6.51 \\
\hline Schneeberger 2015 & & $1.44(0.88,2.36)$ & 14.18 \\
\hline Shen 2016 & & $1.64(1.25,2.15)$ & 17.19 \\
\hline Xu 2016 & & $2.31(1.35,3.94)$ & 13.62 \\
\hline Overall (I-squared=75.8\%, $\mathrm{p}=0.000$ ) & & $1.76(1.21,2.55)$ & 100.00 \\
\hline Note: weights are from random effects analysis & & & \\
\hline 0.0237 & 42.3 & & \\
\hline
\end{tabular}

Figure 3. Association between prevalence of depression in ankylosing spondylitis patients versus control group.

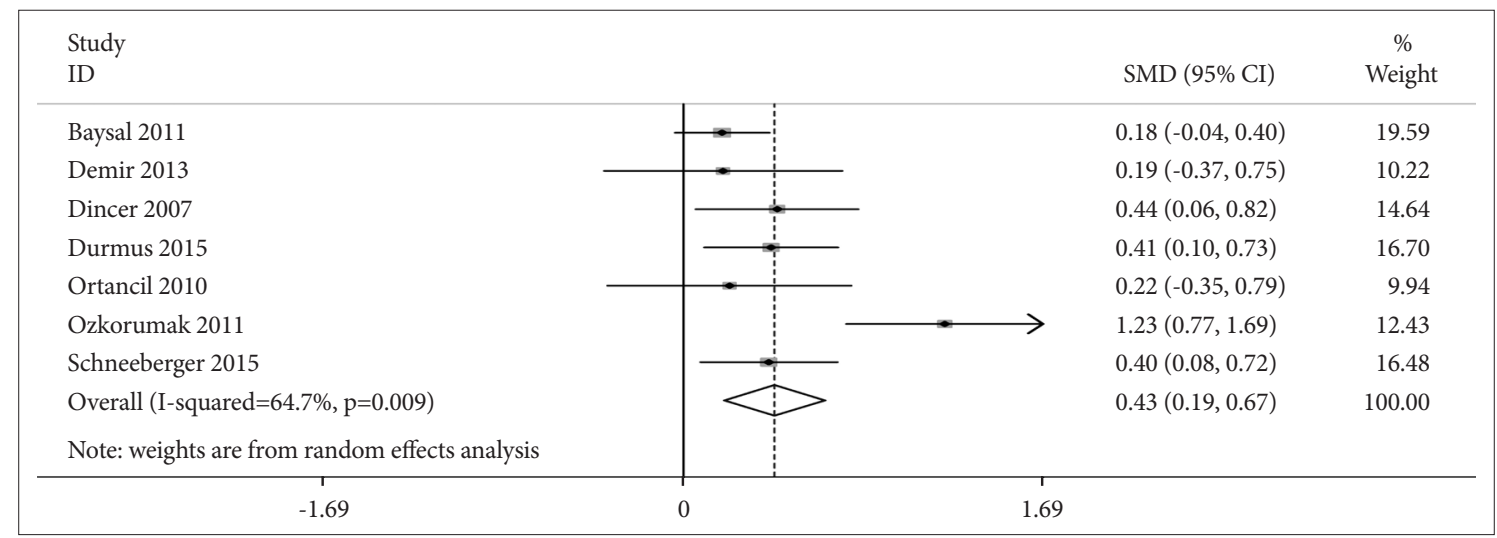

Figure 4. Association between score of depression in ankylosing spondylitis patients versus control group.

country of the studies conducted were significantly associated with increased depression prevalence, which might be explained that small studies often led to high prevalence estimates, and people with low socio-economic status (SES) in developing country was associated with increased susceptibility to depression. ${ }^{19}$

Our sensitivity analyses indicated that depression prevalence estimates were relatively stable. Apart from the measurement tool used to ascertain depression, study quality and study population had impacts on the estimates detected. Our subgroup analyses found that variation in study sample size contributed importantly to the observed heterogeneity in the data. Studies with sample size $<200$ had higher depression estimates according to the HADS with a cutoff of 8 or more. Study quality might be a further explanation for the variance in prevalence estimates. Studies with lower total overall quality scores yielded higher depression estimates using the HADS with thresholds of 8 .

We used rigorous methods to conduct the review and a reproducible, structured approach to data extraction and synthesis. The gold standard method was diagnostic interviews using ICD criteria, which were often time consuming and ex- pensive, therefore, it was not ideal for investigating patients in a busy hospital environment. ${ }^{33}$ Alternatively, self-report screening tools might be used. Although such self-reported questionnaires were quick and easy to complete and cheaper to use than diagnostic interviews in psychiatric practices, the different scales and cutoffs used to define the presence or the absence of depression could vary. ${ }^{33}$ Such nature would lead to information bias and methodological heterogeneity when combining these data in a meta-analysis. It indicated that the rheumatologists should report prevalence at conventional cut-points, and screen for depression among AS patients according to the social and cultural contexts of the rheumatologists and patients in clinical practice.

However, this study still had some limitations. Firstly, a substantial amount of the heterogeneity among the studies remained unexplained by the variables examined. And there was inadequate data to conduct subgroup analyses according to variables of interest such as gender, disease duration and impact of age. A better understanding of social and cultural contexts of AS patients may help elucidate some of the root causes of depressive symptoms. Secondly, the data were derived from studies that used different designs and involved different groups 
Table 4. Impact of study characteristics on prevalence estimates for depression in AS: sensitivity and subgroup analyses

\begin{tabular}{|c|c|c|c|c|c|c|}
\hline & \multicolumn{4}{|c|}{ Prevalence estimates for depression in AS patients } & \multirow{2}{*}{$\begin{array}{c}\text { Prevalence of } \\
\text { depression in AS } \\
\text { patients versus } \\
\text { control group (RR) }\end{array}$} & \multirow{2}{*}{$\begin{array}{l}\text { Scores of depression } \\
\text { in AS patients versus } \\
\text { control group (SMD) }\end{array}$} \\
\hline & $\begin{array}{l}\text { HADS } \\
(\geq 8)\end{array}$ & $\begin{array}{l}\text { HADS } \\
(\geq 11)\end{array}$ & $\begin{array}{l}\text { Zung SDS } \\
\quad(\geq 50)\end{array}$ & $\begin{array}{l}\text { Structured } \\
\text { interview }\end{array}$ & & \\
\hline \multirow[t]{4}{*}{ Primary analysis } & $42(39,45)$ & $9(6,12)$ & $30(15,44)$ & $13(6,20)$ & $1.76(1.21,2.55)$ & $0.43(0.19,0.67)$ \\
\hline & $\mathrm{I}^{2}=91.1 \%$ & $\mathrm{I}^{2}=29.6 \%$ & $\mathrm{I}^{2}=87.0 \%$ & $\mathrm{I}^{2}=98.4 \%$ & $\mathrm{I}^{2}=75.8 \%$ & $\mathrm{I}^{2}=64.7 \%$ \\
\hline & 8 studies & 3 studies & 3 studies & 3 studies & 8 studies & 7 studies \\
\hline & 1,158 AS & 627 AS & 420 AS & 4,232 AS & 3,006 AS/9,925 control & $549 \mathrm{AS} / 428$ control \\
\hline \multicolumn{7}{|l|}{ Sensitivity analyses } \\
\hline $\begin{array}{l}\text { Excluding studies with less } \\
\text { sample representativeness }\end{array}$ & - & - & - & $\begin{array}{l}7(0,13) \\
\mathrm{I}^{2}=98.6 \% \\
2 \text { studies } \\
4,069 \text { AS }\end{array}$ & - & - \\
\hline $\begin{array}{l}\text { Excluding studies with less } \\
\text { comparable respondent and } \\
\text { non-respondent comparability }\end{array}$ & $\begin{array}{c}45(28,62) \\
\mathrm{I}^{2}=91.3 \% \\
3 \text { studies } \\
759 \text { AS }\end{array}$ & $\begin{array}{c}9(5,13) \\
\mathrm{I}^{2}=40.9 \% \\
2 \text { studies } \\
437 \mathrm{AS}\end{array}$ & - & - & - & - \\
\hline \multirow{4}{*}{$\begin{array}{l}\text { Excluding studies only using } \\
\text { male sample }\end{array}$} & $45(34,56)$ & $9(6,12)$ & $30(15,44)$ & $13(6,20)$ & $1.85(1.24,2.75)$ & $0.28(0.13,0.43)$ \\
\hline & $\mathrm{I}^{2}=87.0 \%$ & $\mathrm{I}^{2}=29.6 \%$ & $\mathrm{I}^{2}=87.0 \%$ & $\mathrm{I}^{2}=98.4 \%$ & $\mathrm{I}^{2}=64 \%$ & $\mathrm{I}^{2}=0 \%$ \\
\hline & 6 studies & 3 studies & 3 studies & 3 studies & 7 studies & 5 studies \\
\hline & 948 AS & 627 AS & 358 AS & 4,232 AS & $2,906 \mathrm{AS} / 9,825$ control & $438 \mathrm{AS} / 340$ control \\
\hline \multicolumn{7}{|l|}{ Subgroup analyses } \\
\hline \multicolumn{7}{|l|}{ Sample size } \\
\hline \multirow[t]{4}{*}{$<200$} & $52(44,60)$ & $11(8,15)$ & $23(14,32)$ & - & $3.72(1.33,10.38)$ & $0.49(0.22,0.75)$ \\
\hline & $\mathrm{I}^{2}=70.0 \%$ & $\mathrm{I}^{2}=0 \%$ & $\mathrm{I}^{2}=22.1 \%$ & & $\mathrm{I}^{2}=87 \%$ & $\mathrm{I}^{2}=59 \%$ \\
\hline & 7 studies & 2 studies & 2 studies & & 6 studies & 6 studies \\
\hline & 546 AS & 279 AS & 108 AS & & $432 \mathrm{AS} / 483$ control & $306 \mathrm{AS} / 310$ control \\
\hline \multirow[t]{4}{*}{$\geq 200$} & - & - & - & $7(0,13)$ & $1.48(1.06,2.06)$ & - \\
\hline & & & & $\mathrm{I}^{2}=98.6 \%$ & $\mathrm{I}^{2}=40 \%$ & \\
\hline & & & & 2 studies & 2 studies & \\
\hline & & & & 4,069 AS & 2574 AS/9442 control & \\
\hline \multicolumn{7}{|l|}{ Overall quality } \\
\hline \multirow[t]{4}{*}{$<3$ points (low quality) } & $52(41,63)$ & - & $23(14,32)$ & - & $3.72(1.33,10.38)$ & $0.49(0.22,0.75)$ \\
\hline & $\mathrm{I}^{2}=79.4 \%$ & & $\mathrm{I}^{2}=22.1 \%$ & & $\mathrm{I}^{2}=87 \%$ & $\mathrm{I}^{2}=59 \%$ \\
\hline & 5 studies & & 2 studies & & 6 studies & 6 studies \\
\hline & 399 AS & & $108 \mathrm{AS}$ & & $432 \mathrm{AS} / 483$ control & $306 \mathrm{AS} / 310$ control \\
\hline \multirow[t]{4}{*}{$\geq 3$ points (high quality) } & $45(28,62)$ & $9(5,13)$ & - & $7(0,13)$ & $1.48(1.06,2.06)$ & - \\
\hline & $\mathrm{I}^{2}=91.3 \%$ & $\mathrm{I}^{2}=40.9 \%$ & & $\mathrm{I}^{2}=98.6 \%$ & $\mathrm{I}^{2}=40 \%$ & \\
\hline & 3 studies & 2 studies & & 2 studies & 2 studies & \\
\hline & 759 AS & 437 AS & & 4,069 AS & 2,574 AS/9,442 control & \\
\hline \multicolumn{7}{|l|}{ Publication year } \\
\hline $2000 s$ & $\begin{array}{c}32(29,32) \\
\mathrm{I}^{2}=0 \% \\
2 \text { studies } \\
675 \text { AS }\end{array}$ & - & - & - & - & - \\
\hline \multirow[t]{4}{*}{$2010^{-}$} & $57(52,62)$ & $9(5,12)$ & $30(8,53)$ & $7(0,13)$ & $2.98(1.47,6.06)$ & $0.43(0.15,0.70)$ \\
\hline & $\mathrm{I}^{2}=18.2 \%$ & $\mathrm{I}^{2}=41.7 \%$ & $\mathrm{I}^{2}=92.3 \%$ & $\mathrm{I}^{2}=98.6 \%$ & $\mathrm{I}^{2}=88 \%$ & $\mathrm{I}^{2}=70 \%$ \\
\hline & 6 studies & 2 studies & 2 studies & 2 studies & 7 studies & 6 studies \\
\hline & 483 AS & $538 \mathrm{AS}$ & 358 AS & 4,069 AS & 2,943 AS/9,865 control & $481 \mathrm{AS} / 383$ control \\
\hline
\end{tabular}


Table 4. Impact of study characteristics on prevalence estimates for depression in AS: sensitivity and subgroup analyses (continued)

\begin{tabular}{|c|c|c|c|c|c|c|}
\hline & \multicolumn{4}{|c|}{ Prevalence estimates for depression in AS patients } & \multirow{2}{*}{$\begin{array}{c}\text { Prevalence of } \\
\text { depression in AS } \\
\text { patients versus } \\
\text { control group (RR) }\end{array}$} & \multirow{2}{*}{$\begin{array}{l}\text { Scores of depression } \\
\text { in AS patients versus } \\
\text { control group (SMD) }\end{array}$} \\
\hline & $\begin{array}{l}\text { HADS } \\
(\geq 8)\end{array}$ & $\begin{array}{l}\text { HADS } \\
(\geq 11)\end{array}$ & $\begin{array}{c}\text { Zung SDS } \\
\quad(\geq 50)\end{array}$ & $\begin{array}{l}\text { Structured } \\
\text { interview }\end{array}$ & & \\
\hline \multicolumn{7}{|c|}{ Country of origin } \\
\hline \multirow[t]{4}{*}{ Asia } & $55(41,70)$ & - & $35(22,49)$ & $16(-10,12)$ & $3.27(1.41,7.58)$ & $0.44(0.15,0.72)$ \\
\hline & $\mathrm{I}^{2}=62.0 \%$ & & $\mathrm{I}^{2}=79.7 \%$ & $\mathrm{I}^{2}=98.1 \%$ & $I^{2}=90 \%$ & $\mathrm{I}^{2}=70 \%$ \\
\hline & 3 studies & & 2 studies & 2 studies & 6 studies & 6 studies \\
\hline & $153 \mathrm{AS}$ & & 376 AS & 2,494 AS & 2,879 AS/9,770 control & $485 \mathrm{AS} / 333$ control \\
\hline \multirow[t]{4}{*}{ Europe } & - & $9(6,12)$ & - & - & - & - \\
\hline & & $\mathrm{I}^{2}=29.6 \%$ & & & & \\
\hline & & 3 studies & & & & \\
\hline & & 627 AS & & & & \\
\hline \multirow[t]{4}{*}{ Africa } & $56(50,61)$ & - & - & - & - & - \\
\hline & $\mathrm{I}^{2}=0 \%$ & & & & & \\
\hline & 3 studies & & & & & \\
\hline & 330 AS & & & & & \\
\hline
\end{tabular}

AS: ankylosing spondylitis, HADS: Hospital Anxiety and Depression Scale, SDS: Self-rating Depression Scale, RR: relative risk, SMD: standardized mean difference

Table 5. Pearson's and Spearmen's correlation between study characteristics and prevalence estimates

\begin{tabular}{lccc}
\hline \multirow{2}{*}{ Study characteristic } & \multicolumn{3}{c}{ Depression prevalence estimate } \\
\cline { 2 - 4 } & No. of studies & $\mathrm{r}$ & $\mathrm{p}$ \\
\hline Male, \% & 27 & 0.153 & 0.445 \\
Mean/medium age, year & 27 & -0.054 & 0.790 \\
Mean/medium disease & 27 & -0.035 & 0.861 \\
duration, year & & & \\
Sample size & 28 & $-0.450^{*}$ & 0.016 \\
Representativeness & 28 & -0.215 & 0.272 \\
Comparability & 28 & -0.066 & 0.737 \\
Overall quality & 28 & -0.055 & 0.780 \\
Country of origin & 27 & $-0.613^{\dagger}$ & 0.001 \\
Publication year & 28 & 0.108 & 0.585 \\
\hline
\end{tabular}

${ }^{*} \mathrm{p}<0.05,{ }^{\dagger} \mathrm{p}<0.01$

of patients (e.g., different countries and years of publication), which might result in heterogeneity among the studies. Thirdly, the analysis relied on aggregated published data, which might result in potential publication bias.

\section{CONCLUSIONS}

One-third of people with AS experienced symptoms of depression. Depression was more prevalent in AS patients than in controls. Further research is needed to identify effective strategies for preventing and treating depression among AS patients.

\section{Supplementary Materials}

The online-only Data Supplement is available with this article at https://doi.org/10.30773/pi.2019.06.05.

\section{Acknowledgments}

The authors would like to thank all of the subjects for completing the article. This study was supported by Grants from the Chinese National Natural Science Foundation (Grant no. 71904118).

\section{Conflicts of Interest}

The authors have no potential conflicts of interest to disclose.

\section{Author Contributions}

Conceptualization: Lijuan Zhang. Data curation: Yaping Wu. Formal analysis: Lijuan Zhang. Methodology: Lijuan Zhang. Project administration: Weiyi Zhu. Resources: Shiguang Liu. Software: Yaping Wu. Supervision: Shiguang Liu. Validation: Weiyi Zhu. Writing-original draft: Lijuan Zhang. Writing_review \& editing: Weiyi Zhu.

\section{ORCID iDs}

Shiguang Liu

Weiyi Zhu

Lijuan Zhang

https://orcid.org/0000-0002-5231-7486

https://orcid.org/0000-0002-9964-7239 https://orcid.org/0000-0003-4341-7511

\section{REFERENCES}

1. Braun J, Sieper J. Ankylosing spondylitis. Lancet 2007;369:1379-1390.

2. Shen B, Zhang A, Liu J, Da Z, Xu X, Liu H, et al. Body image disturbance and quality of life in Chinese patients with ankylosing spondylitis. Psychol Psychother 2014;87:324-337.

3. Stubbs B, Aluko Y, Myint PK, Smith TO. Prevalence of depressive symptoms and anxiety in osteoarthritis: a systematic review and metaanalysis. Age Ageing 2016;45:228-235.

4. Mak A, Tang CS, Chan MF, Cheak AA, Ho RC. Damage accrual, cumulative glucocorticoid dose and depression predict anxiety in patients with systemic lupus erythematosus. Clin Rheumatol 2011;30: 795-803. 
5. Zhang L, Xia Y, Zhang Q, Fu T, Yin R, Guo G, et al. The correlations of socioeconomic status, disease activity, quality of life, and depression/ anxiety in Chinese patients with rheumatoid arthritis. Psychol Health Med 2017;22:28-36.

6. Liu Y, Ho RC, Mak A. The role of interleukin (IL)-17 in anxiety and depression of patients with rheumatoid arthritis. Int J Rheum Dis 2012;15:183-187.

7. Xu X, Shen B, Zhang A, Liu J, Da Z, Liu H, et al. Anxiety and depression correlate with disease and quality-of-life parameters in Chinese patients with ankylosing spondylitis. Patient Prefer Adherence 2016; 10:879-885.

8. Lépine JP, Briley M. The increasing burden of depression. Neuropsychiatr Dis Treat 2011;7:3-7.

9. Durmus D, Sarisoy G, Alayli G, Kesmen H, Çetin E, Bilgici A, et al. Psychiatric symptoms in ankylosing spondylitis: their relationship with disease activity, functional capacity, pain and fatigue. Compr Psychiatry 2015;62:170-177.

10. Batmaz I, Sariyildiz MA, Dilek B, Bez Y, Karakoc M, Cevik R. Sleep quality and associated factors in ankylosing spondylitis: relationship with disease parameters, psychological status and quality of life. Rheumatol Int 2013;33:1039-1045.

11. Brionez TF, Assassi S, Reveille JD, Green C, Learch T, Diekman L, et al. Psychological correlates of self-reported disease activity in ankylosing spondylitis. J Rheumatol 2010;37:829-834.

12. Gunaydin R, Goksel Karatepe A, Cesmeli N, Kaya T. Fatigue in patients with ankylosing spondylitis: relationships with disease-specific variables, depression, and sleep disturbance. Clin Rheumatol 2009;28: 1045-1051.

13. Brionez TF, Assassi S, Reveille JD, Learch TJ, Diekman L, Ward MM, et al. Psychological correlates of self-reported functional limitation in patients with ankylosing spondylitis. Arthritis Res Ther 2009;11:R182.

14. Aissaoui N, Rostom S, Hakkou J, Berrada Ghziouel K, Bahiri R, Abouqal $\mathrm{R}$, et al. Fatigue in patients with ankylosing spondylitis: prevalence and relationships with disease-specific variables, psychological status, and sleep disturbance. Rheumatol Int 2012;32:2117-2124.

15. Hakkou J, Rostom S, Aissaoui N, Berrada KR, Abouqal R, Bahiri R, et al. Psychological status in Moroccan patients with ankylosing spondylitis and its relationships with disease parameters and quality of life. J Clin Rheumatol 2011;17:424-428.

16. Ho RC, Mak KK, Chua AN, Ho CS, Mak A. The effect of severity of depressive disorder on economic burden in a university hospital in Singapore. Expert Rev Pharmacoecon Outcomes Res 2013;13:549-559.

17. Shen CC, Hu LY, Yang AC, Kuo BI, Chiang YY, Tsai SJ. Risk of psychiatric disorders following ankylosing spondylitis: a nationwide population-based retrospective cohort study. J Rheumatol 2016;43:625-631.

18. Dhakad U, Singh BP, Das SK, Wakhlu A, Kumar P, Srivastava D, et al. Sexual dysfunctions and lower urinary tract symptoms in ankylosing spondylitis. Int J Rheum Dis 2015;18:866-872.
19. Matcham F, Rayner L, Steer S, Hotopf M. The prevalence of depression in rheumatoid arthritis: a systematic review and meta-analysis. Rheumatology (Oxford) 2013;52:2136-2148.

20. Zhang L, Fu T, Yin R, Zhang Q, Shen B. Prevalence of depression and anxiety in systemic lupus erythematosus: a systematic review and meta-analysis. BMC Psychiatry 2017;17:70.

21. Mak A, Cheung MW, Chiew HJ, Liu Y, Ho RC. Global trend of survival and damage of systemic lupus erythematosus: meta-analysis and meta-regression of observational studies from the 1950s to 2000s. Semin Arthritis Rheum 2012;41:830-839.

22. Mak A, Ho RC, Tng HY, Koh HL, Chong JS, Zhou J. Early cerebral volume reductions and their associations with reduced lupus disease activity in patients with newly-diagnosed systemic lupus erythematosus. Sci Rep 2016;6:22231.

23. Panic N, Leoncini E, de Belvis G, Ricciardi W, Boccia S. Evaluation of the endorsement of the preferred reporting items for systematic reviews and meta-analysis (PRISMA) statement on the quality of published systematic review and meta-analyses. PLoS One 2013;8:e83138.

24. Mata DA, Ramos MA, Bansal N, Khan R, Guille C, Di Angelantonio E, et al. Prevalence of depression and depressive symptoms among resident physicians: a systematic review and meta-analysis. JAMA 2015; 314:2373-2383.

25. Borenstein M, Hedges LV, Higgins JP, Rothstein HR. A basic introduction to fixed-effect and random-effects models for meta-analysis. Res Synth Methods 2010;1:97-111.

26. Cheung MW, Ho RC, Lim Y, Mak A. Conducting a meta-analysis: basics and good practices. Int J Rheum Dis 2012;15:129-135.

27. Higgins JP, Thompson SG, Deeks JJ, Altman DG. Measuring inconsistency in meta-analyses. BMJ 2003;327:557-560.

28. Sterne JA, Egger M. Funnel plots for detecting bias in meta-analysis: guidelines on choice of axis. J Clin Epidemiol 2001;54:1046-1055.

29. Egger M, Davey Smith G, Schneider M, Minder C. Bias in meta-analysis detected by a simple, graphical test. BMJ 1997;315:629-634.

30. Lu Y, Mak KK, van Bever HP, Ng TP, Mak A, Ho RC. Prevalence of anxiety and depressive symptoms in adolescents with asthma: a metaanalysis and meta-regression. Pediatr Allergy Immunol 2012;23:707715.

31. Zhang MW, Ho RC, Cheung MW, Fu E, Mak A. Prevalence of depressive symptoms in patients with chronic obstructive pulmonary disease: a systematic review, meta-analysis and meta-regression. Gen Hosp Psychiatry 2011;33:217-223.

32. Ho RC, Fu EH, Chua AN, Cheak AA, Mak A. Clinical and psychosocial factors associated with depression and anxiety in Singaporean patients with rheumatoid arthritis. Int J Rheum Dis 2011;14:37-47.

33. Hotopf M, Chidgey J, Addington-Hall J, Ly KL. Depression in advanced disease: a systematic review Part 1 . Prevalence and case finding. Palliat Med 2002;16:81-97. 


\section{SUPPLEMENTARY MATERIAL 1}

\section{Search Terms}

Embase/PsyINFO/Web of Science/PubMed/ Cochrane Library

(depress* or depress* disorder\$ or affective disorder\$ or mood disorder\$ or adjustment disorder\$ or affective symptom\$ or dysthymi*) AND (Ankylosing spondylitis or AS) 


\section{SUPPLEMENTARY MATERIAL 2}

\section{Results of the Literature Search}

1. Aissaoui N, Rostom S, Hakkou J, Berrada Ghziouel K, Bahiri R, Abouqal R, et al. Fatigue in patients with ankylosing spondylitis: prevalence and relationships with disease-specific variables, psychological status, and sleep disturbance. Rheumatol Int 2012;32:2117-2124.

2. Altan L, Bingol U, Saranodol A, Asian M, Eican I, Yurtkuran M. Anxiety and depression in ankylosing spondylitis patients. J Rheumatol Med Rehabil 2003;14:221-227.

3. Anyfanti P, Gavriilaki E, Pyrpasopoulou A, Triantafyllou G, Triantafyllou A, Chatzimichailidou S, et al. Depression, anxiety, and quality of life in a large cohort of patients with rheumatic diseases: common, yet undertreated. Clin Rheumatol 2016;35:733-739.

4. Arisoy O, Bes C, Cifci C, Sercan M, Soy M. The effect of TNF-alpha blockers on psychometric measures in ankylosing spondylitis patients: a preliminary observation. Rheumatol Int 2013;33:1855-1864.

5. Aydin T, Taspinar O, Sariyildiz MA, Guneser M, Keskin Y, Canbaz N, et al. Evaluation of the effectiveness of home based or hospital based calisthenic exercises in patients with ankylosing spondylitis. J Back Musculoskelet Rehabil 2016;29:723-730.

6. Baysal O, Durmus B, Ersoy Y, Altay Z, Senel K, Nas K, et al. Relationship between psychological status and disease activity and quality of life in ankylosing spondylitis. Rheumatol Int 2011;31:795-800.

7. Cakar E, Dincer U, Kiralp MZ, Taskaynatan MA, Yasar E, Bayman EO, et al. Sexual problems in male ankylosing spondylitis patients: relationship with functionality, disease activity, quality of life, and emotional status. Clin Rheumatol 2007;26:1607-1613.

8. Cooksey R, Brophy S, Dennis M, Davies H, Atkinson M, Irvine E, et al. Severe flare as a predictor of poor outcome in ankylosing spondylitis: a cohort study using questionnaire and routine data linkage. Rheumatology 2015;54:1563-1572.

9. Demir SE, Rezvani A, Ok S. Assessment of sexual functions in female patients with ankylosing spondylitis compared with healthy controls. Rheumatol Int 2013;33:57-63.

10. Dhakad U, Singh BP, Das SK, Wakhlu A, Kumar P, Srivastava D, et al. Sexual dysfunctions and lower urinary tract symptoms in ankylosing spondylitis. Int J Rheum Dis 2015;18:866-872.

11. Dincer U, Cakar E, Kiralp MZ, Dursun H. Assessment of sexual dysfunction in male patients with Ankylosing Spondylitis. Rheumatol Int 2007;27:561566.

12. Durmus D, Sarisoy G, Alayli G, Kesmen H, Çetin E, Bilgici A, et al. Psychiatric symptoms in ankylosing spondylitis: their relationship with disease activity, functional capacity, pain and fatigue. Compr Psychiatry 2015;62:170-177.

13. Ersozlu-Bozkirli ED, Keskek SO, Bozkirli E, Yucel AE. The effect of infliximab on depressive symptoms in patients with ankylosing spondylitis. Acta Reumatol Port 2015;40:262-267.

14. Ertenli I, Ozer S, Kiraz S, Apras SB, Akdogan A, Karadag O, et al. Infliximab, a TNF-alpha antagonist treatment in patients with ankylosing spondylitis: the impact on depression, anxiety and quality of life level. Rheumatol Int 2012;32:323-330.

15. Fallahi S, Jamshidi AR, Bidad K, Qorbani M, Mahmoudi M. Evaluating the reliability of Persian version of ankylosing spondylitis quality of life (ASQoL) questionnaire and related clinical and demographic parameters in patients with ankylosing spondylitis. Rheumatol Int 2014;34:803-809.

16. Günaydin R, Göksel Karatepe A, Ceşmeli N, Kaya T. Fatigue in patients with ankylosing spondylitis: relationships with disease-specific variables, depression, and sleep disturbance. Clin Rheumatol 2009;28:1045-1051.

17. Hakkou J, Rostom S, Aissaoui N, Berrada KR, Abouqal R, Bahiri R, et al. Psychological status in Moroccan patients with Ankylosing Spondylitis and its relationships with disease parameters and quality of life. J Clin Rheumatol 2011;17:424-428.

18. Healey EL, Haywood KL, Jordan KP, Garratt AM, Ryan S, Packham JC. Ankylosing spondylitis and its impact on sexual relationships. Rheumatology 2009;48:1378-1381.

19. Hyphantis T, Kotsis K, Tsifetaki N, Creed F, Drosos AA, Carvalho AF, et al. The relationship between depressive symptoms, illness perceptions and quality of life in ankylosing spondylitis in comparison to rheumatoid arthritis. Clin Rheumatol 2013;32:635-644.

20. Jiang YT, Yang MC, Wu HS, Song H, Zhan F, Liu SY, et al. The relationship between disease activity measured by the BASDAI and psychological status, stressful life events, and sleep quality in ankylosing spondylitis. Clin Rheumatol 2015;34:503-510.

21. Li Y, Zhang SL, Zhu J, Du XN, Huang F. Sleep disturbances are associated with increased pain, disease activity, depression, and anxiety in ankylosing spondylitis: a case-control study. Arthritis Res Ther 2012;14:R215.

22. Lian XF, Tang YQ, Zhang C. The investgation of depression in 60 ankylosing spondylitis patients. Nurs J Chin People Liberat Army 2003;20:39-40.

23. Martindale J, Smith J, Sutton CJ, Grennan D, Goodacre L, Goodacre JA. Disease and psychological status in ankylosing spondylitis. Rheumatology 2006; $45: 1288-1293$.

24. Meesters JJ, Bremander A, Bergman S, Petersson IF, Turkiewicz A, Englund M. The risk for depression in patients with ankylosing spondylitis: a population-based cohort study. Arthritis Res Ther 2014;16:418.

25. Ortancil O, Konuk N, May H, Sanli A, Ozturk D, Ankarali H. Psychological status and patient-assessed health instruments in ankylosing spondylitis. J Clin Rheumatol 2010;16:313-316.

26. Ozkorumak E, Karkucak M, Civil F, Tiryaki A, Ozden G. Sexual function in male patients with ankylosing spondylitis. Int J Impot Res 2011;23:262-267.

27. Rodriguez-Lozano C, Gantes MA, Gonzalez B, Hernandez-Beriain JA, Naranjo A, Hernandez V, et al. Patient-acceptable symptom state as an outcome measure in the daily care of patients with Ankylosing Spondylitis. J Rheumatol 2012;39:1424-1432.

28. Rostom S, Mengat M, Mawani N, Jinane H, Bahiri R, Hajjaj-Hassouni N. Sexual activity in Moroccan men with ankylosing spondylitis. Rheumatol Int 2013;33:1469-1474.

29. Schneeberger EE, Marengo MF, Dal Pra F, Maldonado Cocco JA, Citera G. Fatigue assessment and its impact in the quality of life of patients with ankylosing spondylitis. Clin Rheumatol 2015;34:497-501.

30. Shen CC, Hu LY, Yang AC, Kuo BI, Chiang YY, Tsai SJ. Risk of psychiatric disorders following Ankylosing Spondylitis: a nationwide population-based retrospective cohort study. J Rheumatol 2016;43:625-631.

31. Xu X, Shen B, Zhang A, Liu J, Da Z, Liu H, et al. Anxiety and depression correlate with disease and quality-of-life parameters in Chinese patients with ankylosing spondylitis. Patient Prefer Adherence 2016;10:879-885. 
Supplementary Table 1. Results of newcastle-ottawa risk of bias assessment

\begin{tabular}{|c|c|c|c|c|c|c|}
\hline Study ID & Representativeness & Size & Comparability & Outcome & Statistics & Tota \\
\hline Aissaoui 2012 & 0 & 0 & 0 & 1 & 1 & 2 \\
\hline Altan 2003 & 0 & 0 & 0 & 1 & 0 & 1 \\
\hline Anyfanti 2012 & 0 & 0 & 0 & 1 & 0 & 1 \\
\hline Arısoy 2013 & 0 & 0 & 0 & 1 & 1 & 2 \\
\hline Aydın 2016 & 0 & 0 & 1 & 1 & 1 & 3 \\
\hline Baysal 2011 & 0 & 1 & 0 & 1 & 1 & 3 \\
\hline Cakar 2007 & 0 & 0 & 0 & 1 & 1 & 2 \\
\hline Cooksey 2015 & 0 & 1 & 1 & 1 & 1 & 4 \\
\hline Demir 2013 & 0 & 0 & 0 & 1 & 1 & 2 \\
\hline Dhakad 2015 & 0 & 0 & 0 & 1 & 1 & 2 \\
\hline Dincer 2007 & 0 & 0 & 0 & 1 & 0 & 1 \\
\hline Durmus 2015 & 0 & 0 & 0 & 1 & 1 & 2 \\
\hline Ertenli 2012 & 0 & 0 & 0 & 1 & 1 & 2 \\
\hline Ersözlü-Bozkırlı 2015 & 0 & 0 & 0 & 1 & 1 & 2 \\
\hline Fallahi 2014 & 0 & 0 & 0 & 1 & 1 & 2 \\
\hline Günaydin 2009 & 0 & 0 & 0 & 1 & 1 & 2 \\
\hline Hakkou 2011 & 0 & 0 & 0 & 1 & 1 & 2 \\
\hline Healey 2009 & 1 & 1 & 1 & 1 & 1 & 5 \\
\hline Hyphantis 2013 & 0 & 0 & 0 & 1 & 1 & 2 \\
\hline Jiang 2015 & 1 & 1 & 0 & 1 & 1 & 4 \\
\hline Li 2013 & 0 & 1 & 1 & 1 & 1 & 4 \\
\hline Lian 2003 & 0 & 0 & 0 & 1 & 1 & 2 \\
\hline Martindale 2006 & 0 & 0 & 1 & 1 & 1 & 3 \\
\hline Meesters 2014 & 1 & 1 & 0 & 1 & 0 & 3 \\
\hline Ortancil 2010 & 0 & 0 & 0 & 1 & 1 & 2 \\
\hline Ozkorumak 2011 & 0 & 0 & 0 & 1 & 1 & 2 \\
\hline Rodríguez-Lozano 2012 & 0 & 0 & 0 & 1 & 1 & 2 \\
\hline Rostom 2013 & 0 & 0 & 1 & 1 & 1 & 3 \\
\hline Schneeberger 2015 & 0 & 0 & 0 & 1 & 1 & 2 \\
\hline Shen 2016 & 1 & 1 & 0 & 1 & 0 & 3 \\
\hline Xu 2016 & 0 & 0 & 1 & 1 & 0 & 2 \\
\hline
\end{tabular}




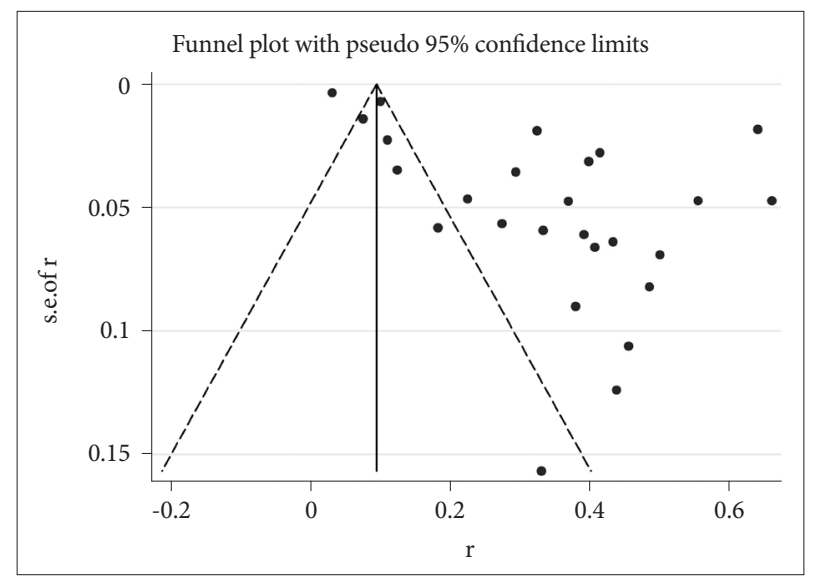

Supplementary Figure 1. Assessment of publication bias. 